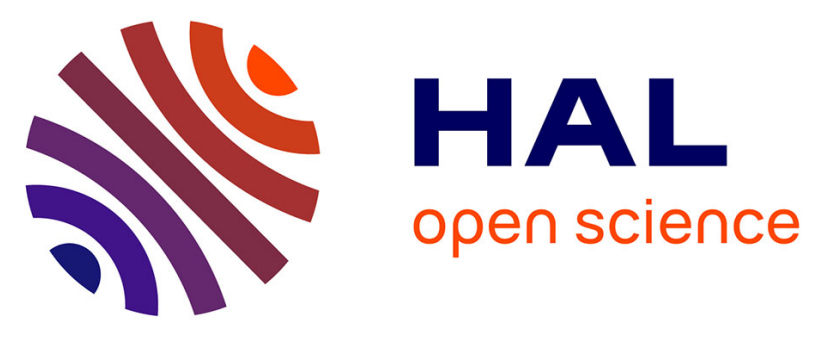

\title{
Modelling, identification and control of a Langevin transducer
}

\author{
Sofiane Ghenna, Frédéric Giraud, Christophe Giraud-Audine, Michel Amberg, \\ Betty Lemaire-Semail
}

\section{- To cite this version:}

Sofiane Ghenna, Frédéric Giraud, Christophe Giraud-Audine, Michel Amberg, Betty Lemaire-Semail. Modelling, identification and control of a Langevin transducer. 2015 IEEE International Workshop of Electronics, Control, Measurement, Signals and their application to Mechatronics, Jun 2015, leberec, Czech Republic. 10.1109/ECMSM.2015.7208676 . hal-01201879

\section{HAL Id: hal-01201879 \\ https://inria.hal.science/hal-01201879}

Submitted on 18 Sep 2015

HAL is a multi-disciplinary open access archive for the deposit and dissemination of scientific research documents, whether they are published or not. The documents may come from teaching and research institutions in France or abroad, or from public or private research centers.
L'archive ouverte pluridisciplinaire HAL, est destinée au dépôt et à la diffusion de documents scientifiques de niveau recherche, publiés ou non, émanant des établissements d'enseignement et de recherche français ou étrangers, des laboratoires publics ou privés. 


\title{
Modelling, identification and control of a Langevin transducer
}

\author{
Sofiane GHENNA ${ }^{1,2}$, Frédéric GIRAUD ${ }^{1,2}$, Christophe GIRAUD-AUDINE ${ }^{1,3}$, \\ Michel AMBERG ${ }^{1,2}$, and Betty LEMAIRE-SEMAIL ${ }^{1,2}$ \\ ${ }^{1}$ Laboratoire d'Electrotechnique et d'Electronique de Puissance \\ IRCICA, 50 avenue Halley, 59650 Villeneuve d'Ascq, France \\ ${ }^{2}$ Université Lille1, 59650 Villeneuve d'Ascq, France \\ 3 Arts et Métiers Paris-Tech \\ Centre de Lille, 8 bd Louis XIV, 59046 Lille
}

\begin{abstract}
The control of the vibration amplitude, and the resonance frequency tracking for ultrasonic transducer have been established. However, some applications require to control the vibration amplitude and its relative phase at a fixed frequency as the generation of travelling wave. In this paper, the transducer is modelled in rotating frame, and the decoupling according to two-axis allows to obtain a double independent closed loop control to address this issue. It is possible to control the transducer vibration amplitude and its relative phase, in steady state even in transient by acting on the amplitude of the supply voltage. Thanks to vector control method. This approach will be confirmed with experimental and simulation results.
\end{abstract}

Keywords: Langevin ultrasonic transducer; Vector control; modelling in a rotating reference frame; Control of piezoactuator; Identification of piezo-actuator; piezoelectricity.

\section{INTRODUCTION}

Currently the piezoelectric actuators take a prominent place in several fields (medicine, industry, aeronautics ...). Even if their role is important, the control of their vibration amplitude is still an issue. Several studies have been done on the control of the piezoelectric actuators by changing the supply voltage amplitude, or frequency. The control described in [1] introduces two control methods to regulate only the vibration amplitude using PI and PID controllers for machining application. In forging processes, it is possible to control the vibration velocity in quasi-static state [2]. In [3] a resonance frequency tracking system is introduced using digital circuits, by direct measurement of the phase difference between the applied voltage and the input current, the transducer is controlled at the resonant frequency. However the vibration amplitude is not controlled. In another method, the vibration motion is described in a rotating reference frame [4], and then the control of vibration amplitude can be deduced by a simple transfer function between the supply voltage and the vibration amplitude [5][6][7]. The control of the vibration amplitude is established in rotating frame related to the wave. However the voltage is kept constant, then controlling the phase shift between the voltage and the wave amplitude allows the tracking of the resonant frequency. Some applications such as object transport using flexural ultrasonic travelling wave, require to control the phase and the frequency of the vibration amplitude
[8][9]. The first is the dominant factor to determine direction of the travelling wave, while the second is used to determine the transport speed. Therefore, the control of the vibration and its relative phase at a predefined frequency are necessary. In this paper, a rotating reference frame related to the frequency of the vibration wave is introduced. The complex notation of different physical variables, and the decoupling according to two-axis allow a double independent closed loop control to regulate the real and imaginary parts of the vibration amplitude, and its relative phase. At any frequency, at the resonance or not. It acts directly on the amplitude of the supply voltage as a classical electromagnetic machines [10].

In the first part, the Langevin transducer and the classical electromechanical modelling are reminded. In the second part, the modelling of the vibration amplitude in rotating frame is addressed. The identification of Langevin parameters is described in the third part. Finally the control of the vibration amplitude is illustrated with experimental and simulation results in the last part.

\section{LANGEVIN TYPE TRANSDUCER}

Langevin transducer was invented in 1922 [11] by Paul Langevin. Its current scope of use has significantly expanded due to its high power ratio and high energy conversion efficiency, especially for ultrasonic cleaning [12][13], Cut or welding of thermoplastics [14][15]. It is non-magnetic material which it is useful in MRI (Magnetic resonance imaging) environment for example[16]. This resonator consists of two piezoelectric ceramics longitudinally polarized in opposite directions; the deformations are operated in the polarization direction, which adds the deformation of both of them. These ceramics are connected mechanically in series and electrically in parallel, sandwiched between two metal masses, generally aluminium, due to the large acoustic transmission properties and its ease of manufacturing. These masses are held by a preload bolt [17] which allows pre-loading the ceramics to prevent undesirable tensile stress; they are also used to calibrate the acoustic set at a predefined frequency. 


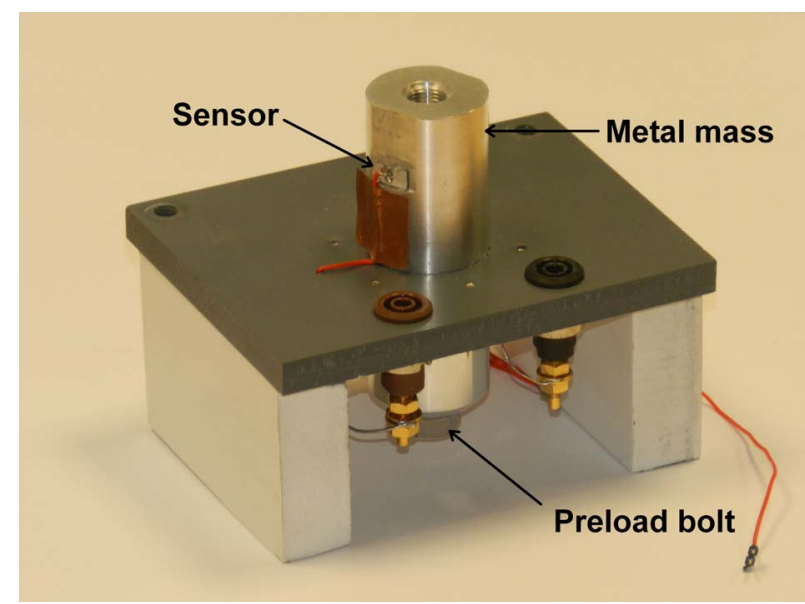

Fig. 1. Picture of the Langevin-type transducer

\section{A. Electromechanical modelling}

To determine the electromechanical equivalent circuit of the transducer, we will use the propagation of elastic waves through a metal [18] in general, then adding the equations of piezoelectricity to describe the piezoelectric ceramic stress [19]. The equivalent electromechanical circuit of the Langevin transducer, according to the Mason's model is given in Fig.2

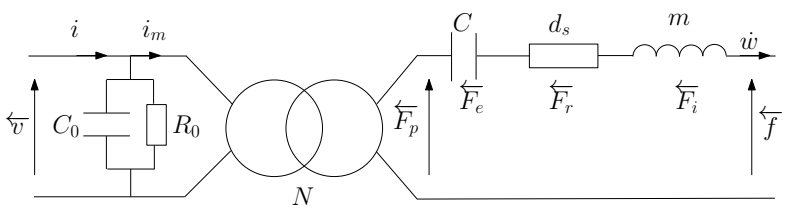

Fig. 2. Electromechanical equivalent circuit of the piezoelectric actuator in vicinity of the resonance

The modelling of the electromechanical coupling uses an ideal transformer, with a transformer ratio $N$. The electrical variables are voltage $v$, current $i$, and $i_{m}$ is the motional current, $R_{0}$ and $C_{0}$ represent the dielectric loss and capacitance respectively. The mechanical variables are force $f$, and velocity $\dot{w}$. The current flowing in the secondary is analogous to the velocity $\dot{w}$. The vibrating mass $m$ is equivalent to an inductance, a kinetic force or inertia related to the vibrating actuator and reflects the dynamic nature of the structure mass noted $F_{i}$, while the stiffness of the element takes the form of a capacitance $c$, resulting in an elastic force $F_{e}$. The dissipation phenomena of mechanical origin results in damping $d_{s}$ which is equivalent to a series resistance [5]. The corresponding forces are denoted $F_{r}$. The equation of motion about a vibration mode is given by:

$$
m \ddot{w}+d_{s} \dot{w}+c w=N v-f
$$

$w, \dot{w}$ and $\ddot{w}$ are displacement, velocity and acceleration respectively.

The equation eq. 1 describes the behaviour of the vibration amplitude; it is a second order equation, forced by the voltage $v$ and the external forces $f$. Thereafter this modell ing will be established in a rotating reference frame in order to obtain the transfer functions needed for the control.

\section{MODEL OF THE VIBRATION AMPLITUDE OF THE LANGEVIN TRANSDUCER IN A ROTATING REFERENCE FRAME}

\section{A. Equation of vibration domain in a rotating reference frame}

In this paper, only harmonic vibrations are considered enabling the use of the complex notation in eq. 1 with $\underline{x}=\underline{X} e^{j \omega t}$, where $\underline{X}=X e^{j \alpha}, \alpha$ and $X$ are respectively the argument and the magnitude of $\underline{X}$ so much that:

$$
m \underline{\ddot{w}}+d_{s} \underline{\dot{w}}+c \underline{w}=N \underline{v}-\underline{f}
$$

The vibration amplitude, the supply voltage and the force generated by the actuator being respectively defined by:

$$
\begin{aligned}
& \underline{w}=\left(W_{d}+j W_{q}\right) e^{j \omega t} \\
& \underline{v}=\left(V_{d}+j V_{q}\right) e^{j \omega t} \\
& \underline{f}=\left(F_{d}+j F_{q}\right) e^{j \omega t}
\end{aligned}
$$

where $\omega$ is the angular frequency and $j=\sqrt{-1}$. This transformation can be illustrated as in figure 3 . In this figure the vectors $\underline{V}$ and $\underline{W}$ are rotating in the fixed frame, and fixed in the $(d, q)$ frame.

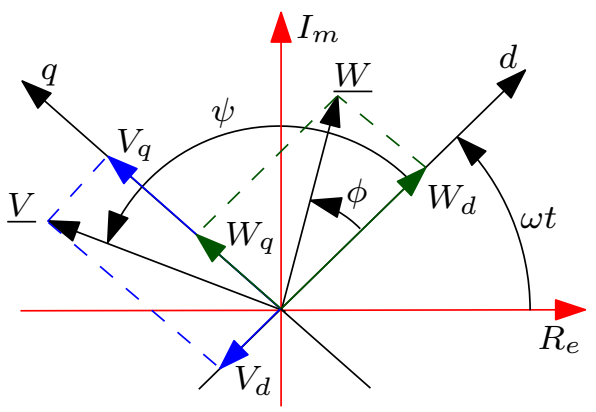

Fig. 3. Vibration amplitude and voltage in a rotating reference frame

By substituting the relation eq. 3 in eq. 2 with :

$$
\begin{gathered}
\dot{\dot{w}}=\left[\left(\dot{W}_{d}+j \dot{W}_{q}\right)+j \omega\left(W_{d}+j W_{q}\right)\right] e^{j \omega t} \\
\ddot{w}=\left[\left(\ddot{W}_{d}+j \dot{W}_{q}\right)+2 j \omega\left(\dot{W}_{d}+j \dot{W}_{q}\right)-\omega^{2}\left(W_{d}+j W_{q}\right)\right] e^{j \omega t}
\end{gathered}
$$

Along the $\mathrm{d}$ axis and q-axis yields:

$$
\begin{aligned}
& m \ddot{W}_{d}+d_{s} \dot{W}_{d}+\left(c-m \omega^{2}\right) W_{d}-\omega\left(2 m \dot{W}_{q}+d_{s} W_{q}\right)=N V_{d}-F_{d} \\
& m \ddot{W}_{q}+d_{s} \dot{W}_{q}+\left(c-m \omega^{2}\right) W_{q}+\omega\left(2 m \dot{W}_{d}+d_{s} W_{d}\right)=N V_{q}-F_{q}
\end{aligned}
$$

In this paper it is admitted that: $\ddot{W}_{d}<<2 \omega \dot{W}_{q}$ and $\dot{W}_{d}<<$ $2 \omega W_{q}$ also $\ddot{W}_{q}<<2 \omega \dot{W}_{d}$ and $\dot{W}_{q}<<2 \omega W_{d}$. Moreover, $F_{d}, F_{q}$ are perturbations, these assumptions lead to consider the following simplified equations:

$$
\begin{aligned}
& \left(c-m \omega^{2}\right) W_{d}-\omega\left(2 m \dot{W}_{q}+d_{s} \dot{W}_{q}\right)=N V_{d} \\
& \left(c-m \omega^{2}\right) W_{q}-\omega\left(2 m \dot{W}_{d}+d_{s} \dot{W}_{d}\right)=N V_{q}
\end{aligned}
$$




\section{IDENTIFICATION OF A LANGEVIN PARAMETERS NEAR RESONANCE}

\section{A. Dielectric loss $R_{0}$ and blocking capacitance $C_{0}$}

The dielectric resistance $R_{0}$ and the blocking capacitance $C_{0}$ can be determined by measuring the magnitude and phase of the impedance $|Z|$ or the admittance $|Y|$, while varying the excitation frequency accordingly to [11], using a Dynamic Signal Analyzer accordingly to the schematic Stanford Research - SR785.

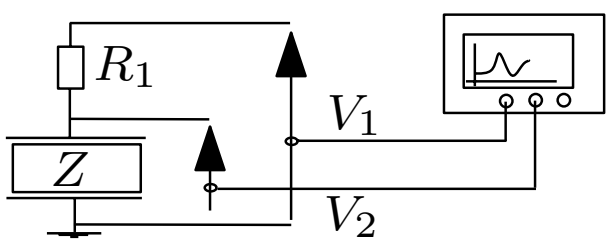

Fig. 4. Schematic diagram for measurement of a Langevin transducer electrical impedance

$$
\underline{\underline{V_{1}}}=\underline{G}=\frac{\underline{Z}}{R_{1}+\underline{Z}}
$$

$G$ is the voltage gain, then the impedance of transducer is given by:

$$
\underline{Z}=\frac{R_{1} \underline{G}}{1-\underline{G}}
$$

The Measured and the predicted transducer admittance are shown in Fig.5

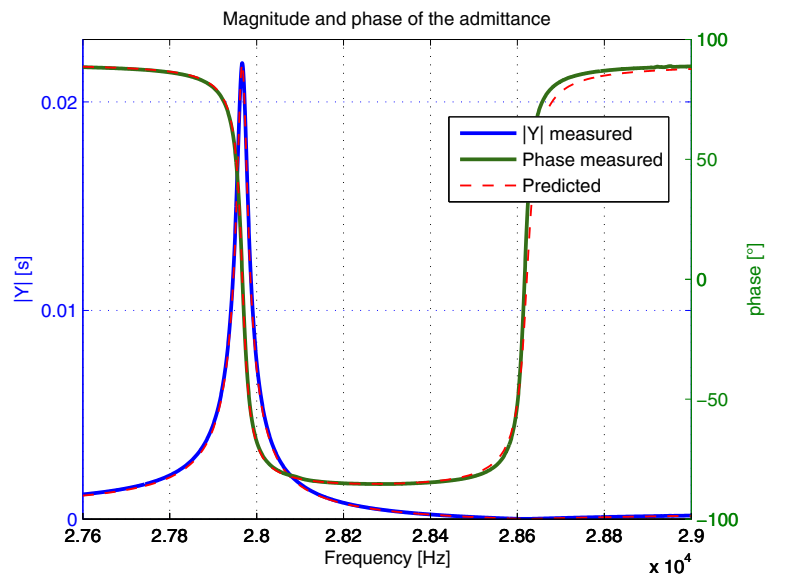

Fig. 5. Admittance and phase of the langevin transducer

The resistance value is identified by the admittance at low frequency

$$
R_{0}=\frac{1}{\operatorname{Real}\left[(Y)_{\min }\right]}
$$

the clamped capacitance is given by:

$$
C_{0}=\frac{\operatorname{Imag}\left[Y\left(\omega_{r}\right)\right]}{\omega_{r}}
$$

where $\omega_{r}$ is resonant angular frequency, the other parameters will be determined in the operating conditions because of the non-linear behaviour of this transducer.

\section{B. Transformer Ratio $N$}

The transformer Ratio can be identified by measuring the ratio between the motional current $i_{m}$ and the vibration velocity $\dot{w}$, as shown in Fig.6

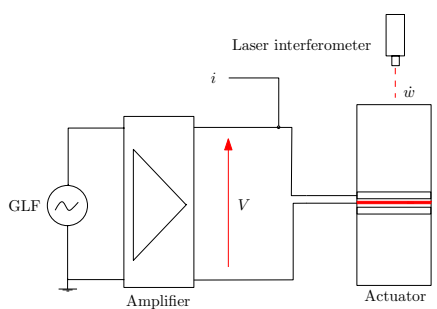

Fig. 6. Schematic diagram for measurement of the transformer ratio

From the equivalent electrical circuit

$$
i(t)=i_{C 0}(t)+i_{m}(t)
$$

with

$$
i_{C_{0}}(t)=C_{0} \frac{\mathrm{d} V_{c}(t)}{\mathrm{d} t}
$$

then

$$
i(t)=C_{0} \frac{\mathrm{d} V_{c}(t)}{\mathrm{d} t}+i_{m}(t)
$$

at the time when $C_{0} \frac{\mathrm{d} V_{c}(t)}{\mathrm{d} t}=0\left(\max\right.$ or min of $\left.V_{c}(t)\right)$ the measured current $i(t)$ is equal to $i_{m}(t)$ then

$$
N=\frac{i_{m}(t)}{\dot{w}(t)}
$$

By a direct measurement of the current, the supply voltage and the vibration velocity of the actuator thanks to interferometer (OFV-525/-5000-S), when the voltage supply is maximum or minimum we determine the transformer ratio as shown in Fig.7

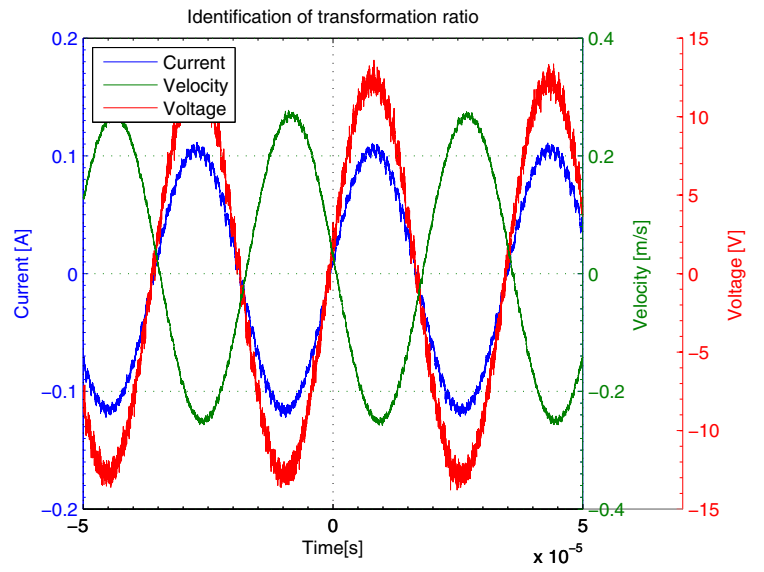

Fig. 7. Identification of the transformer ratio 


\section{Identification of the transfer function near resonance}

The identification of parameters is established in the vicinity of the resonance, therefore the coupling term $\left(c-m \omega^{2}\right) W_{d}$ is small and can be neglected, or considered as perturbation. Then eq. 7 and eq. 8 become:

$$
\begin{aligned}
& -\omega\left(2 m \dot{W}_{q}+d_{s} \dot{W}_{q}\right)=N V_{d} \\
& +\omega\left(2 m \dot{W}_{d}+d_{s} \dot{W}_{d}\right)=N V_{q}
\end{aligned}
$$

The Laplace transformation gives rise to a first order equation:

$$
\begin{aligned}
& \frac{W_{d}}{V_{q}}=\frac{G}{1+\tau_{s}} \\
& \frac{W_{q}}{V_{d}}=\frac{-G}{1+\tau_{s}}
\end{aligned}
$$

with :

$$
G=\frac{N}{d_{s} \omega}
$$

and

$$
\tau=\frac{2 m}{d_{s}}
$$

To determine the parameters of the transfer function, the actuator is placed at resonance (in open loop). The behaviour predicted by eq. 19 and eq. 20 is confirmed by the experimental results, which are obtained at resonance $\left(\omega=\omega_{0}\right.$, with $\left.\omega_{0}=\sqrt{\frac{c}{m}}\right)$ and for a step variation of $V_{q}=5 \mathrm{~V}$ starting from different set points, to test the non-linearity of the transducer.

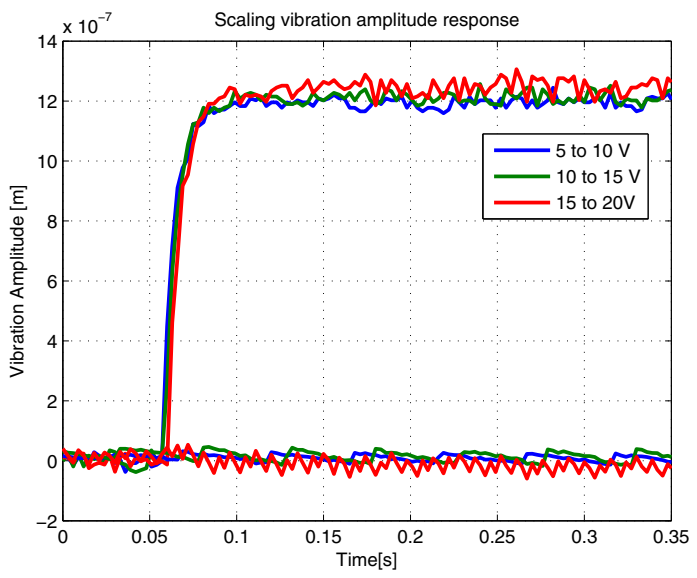

Fig. 8. Scaling vibration amplitude response according to the rising edge $V_{q}$

This result confirms the robustness of the model and the linearity of transducer around the resonance, and will be used to determine the parameters of equation eq.19, gain $\mathrm{G}$ and time constant $\tau$. The identified parameters of transducer are summarized in tab.I.

These identified parameters will be used to calculate the regulators needed for the control of vibration amplitude, and use them in the simulation phase to compare the experimental curves with theoretical results.
TABLE I

PARAMETERS OF THE ACTUATOR IN THE VICINITY OF RESONANCE

\begin{tabular}{|c|c|}
\hline$G[\mathrm{~nm} / \mathrm{V}]$ & 149.30 \\
\hline$\tau[\mathrm{ms}]$ & 8.50 \\
\hline$d_{s}\left[\mathrm{Nm}^{-1} s^{-1}\right]$ & 58.41 \\
\hline$m[\mathrm{~kg}]$ & 0.249 \\
\hline$c\left[10^{9} N / m\right]$ & 7.64 \\
\hline$f[\mathrm{kHz}]$ & 27.93 \\
\hline$C_{0}[\mathrm{pF}]$ & 2.3619 \\
\hline$R_{0}[\mathrm{k} \Omega]$ & 318.34 \\
\hline$N[\mathrm{~A} / \mathrm{m} / \mathrm{s}]$ & 0.45 \\
\hline
\end{tabular}

\section{CONTROL OF VIBRATION'S AMPLITUDE OF THE LANGEVIN TRANSDUCER}

To improve accuracy and robustness of the system, a closed loop control of $W_{d}$ and $W_{q}$ is applied. The voltage $V_{q}$ is used to control the vibration amplitude $W_{d}$ eq.17, while $V_{d}$ is used to control the vibration amplitude $W_{q}$ eq.18, through a regulator $C(s)$ for each closed loop. This control does not depend on frequency, because the vibration amplitude is not aligned to the $d$ axis which is related to the frequency. In figure 10 the closed loop is applied by acting on the amplitude of the supply, and the angular frequency is rejected as perturbation. In order to measure the vibration amplitude, a piezoelectric

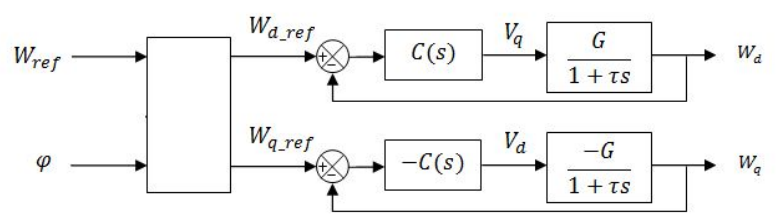

Fig. 9. schematic diagram control of the Langevin transducer

patch was glued in the metal mass of the actuator, to give the image of its vibrations (Fig.1); it is used as a sensor under the direct piezoelectric effect. A DSP (Texas Instrument TMS320F2812), which is featuring digital to analogue converter measures $W_{d}, W_{q}$ and calculates the required value for $V_{q}$ and $V_{d}$. It is also equipped with an analogue-digital converter for processing the measured quantities (vibrations), and a Direct Digital Synthesizer (DDS) for generating a sinusoidal signal which is amplified using a linear amplifier. The description of the system is given in Fig.10, $R_{e}$ is the real part of the voltage and PI (proportional integral). The measured $W_{d}$ and $W_{q}$ are obtained in rotating frame through the voltage patch detailed here after.

\section{A. Reconstitution of the vibration amplitude in rotating frame}

The piezoelectric patch generates a sinusoidal voltage V, accordingly to the direct piezoelectric effect. the real part of this voltage in a rotating reference frame is given by:

$$
V=V_{D} \cos (\omega t)-V_{Q} \sin (\omega t)
$$




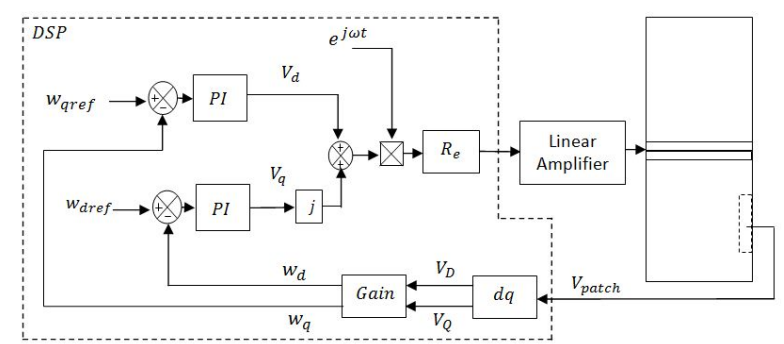

Fig. 10. Block diagram control of the Langevin transducer in rotating frame

In order to extract $V_{D}$ and $V_{Q}$ from the voltage $V_{\text {patch }}$, specific measurements are performed at $\omega t=n \frac{\pi}{2}$ where $n$ is an integer, as shown in Fig.11

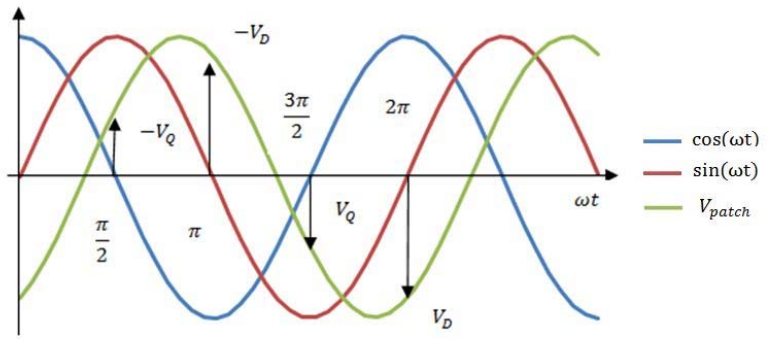

Fig. 11. Reconstitution of the vibration amplitude

Through the identified gain, we determine the values of the vibration amplitude in rotating reference frame. Assuming a linear relationship between the vibration of transducer and the patch voltage, we can write:

$$
\begin{aligned}
& W_{d}=\text { Gain. } V_{D} \\
& W_{q}=\text { Gain. } V_{Q}
\end{aligned}
$$

To identify these relations, steps of voltage amplitude are applied to the transducer, and we measure the vibration amplitude and the patch voltage corresponding to these steps accordingly to Fig.12. From this result the vibration amplitude of the transducer depends linearly on the voltage amplitude of the piezo patch. Therefore the vibration amplitude in rotating frame can be calculated.

$$
\underline{w}=W e^{j \Phi}
$$

where $W=\sqrt{W_{d}^{2}+W_{q}^{2}}$ and $\Phi=\arctan \frac{W_{q}}{W_{d}}$ are respectively the magnitude and the argument of $\underline{w}$.

\section{B. results and discussion}

For a reference step amplitude $W_{\text {dref }}$ from 1 to $2 \mu \mathrm{m}$, and for a reference $W_{\text {qref }}=0$, ie a step of $W$ from 1 to $2 \mu \mathrm{m}$ with $\Phi=0$. The experimental values are well predicted by the model for the real and imaginary part of the vibration amplitude, and follow well the desired vibration as shown in Fig.13. During the test, we applied a normal force on the transducer, this force or this load is rejected as a perturbation.

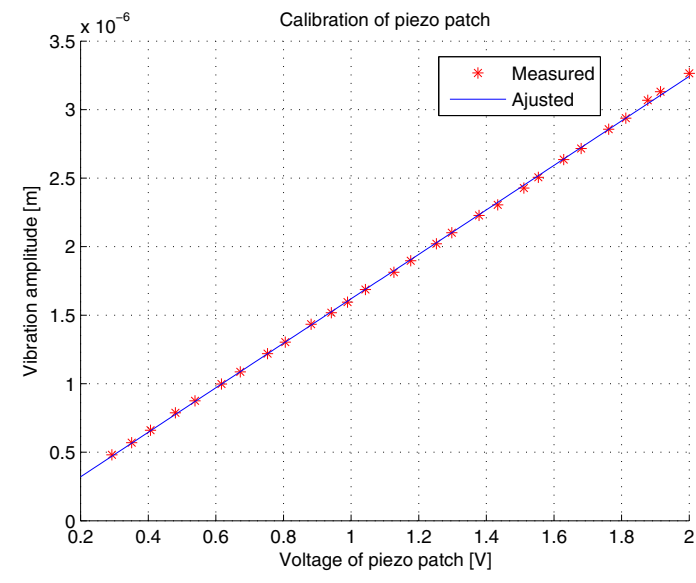

Fig. 12. linear fitting of the vibration amplitude as a function of the patch voltage

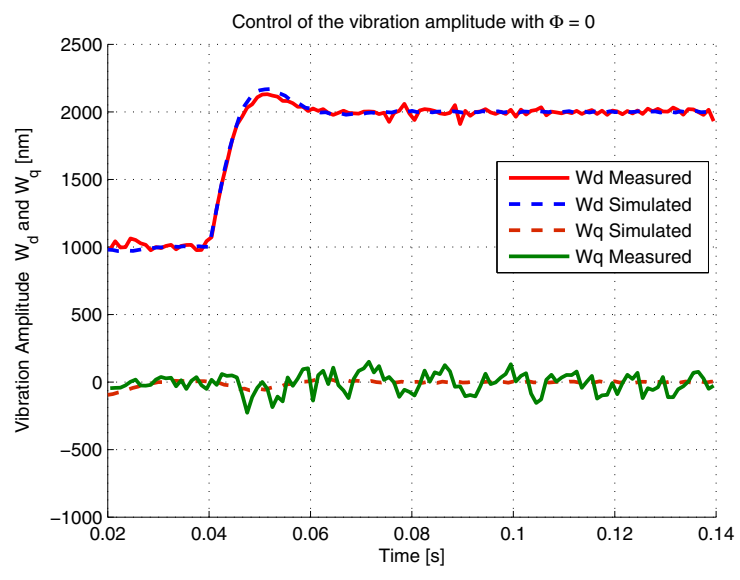

Fig. 13. Vibration amplitude $W_{d}$ and $W_{q}$ in a rotating frame with $\Phi=0$

Fig.14 shows the supply voltage of the transducer (outputs of regulators), the vibration amplitude $W_{q}$ is controlled to zero; the imaginary component $V_{d}$ is present to compensate the coupling term with $W_{d}$ (eq.7) when the system does not operate at its resonance frequency as depicted in eq.7. Figure 15 depicts the evolution of $W_{d}$ and $W_{q}$ as a function of time with a step amplitude from 1 to $2 \mu \mathrm{m}$, but here the phase $\Phi$ is fixed to $\frac{\pi}{4},\left(W_{d}=W_{q}\right)$. The measured values fit also well with the simulated values, and the results shows that $W_{d}$ and $W_{q}$ have the same dynamics.

Figure 16 confirms the results, $V_{d}$ and $V_{q}$ have the same dynamic symmetrically because they have opposed transfer function.

\section{CONCLUSION}

A Langevin transducer model is described in a rotating reference frame, based on the model of the equivalent electric circuit near the resonance. This method allows a dynamic and independent control of the vibration amplitude and its phase relative, in steady state and in transient. The rotating frame is related to the frequency, then this control does not depend 


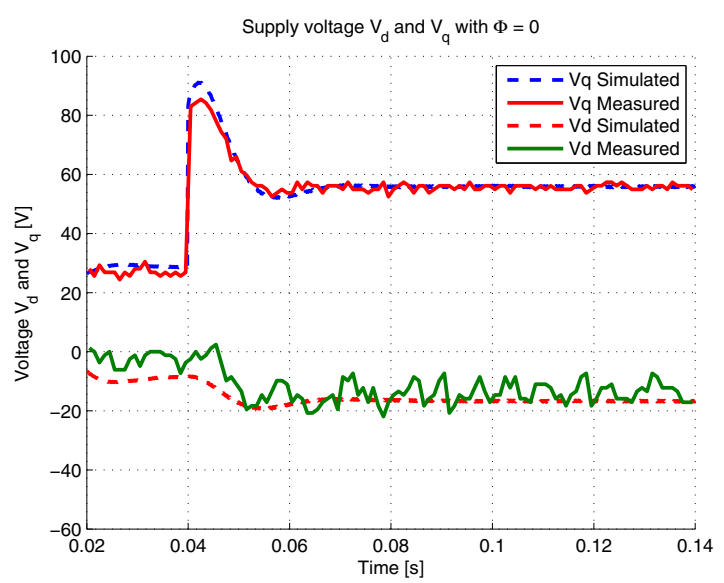

Fig. 14. Supply voltage $V_{d}$ and $V_{q}$ in a rotating frame $\Phi=0$

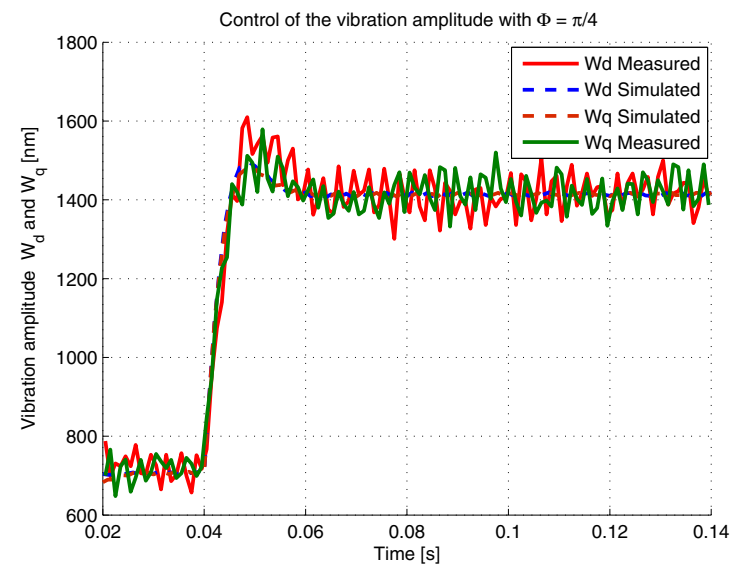

Fig. 15. Vibration amplitude $W_{d}$ and $W_{q}$ in a rotating frame with $\Phi=\pi / 4$

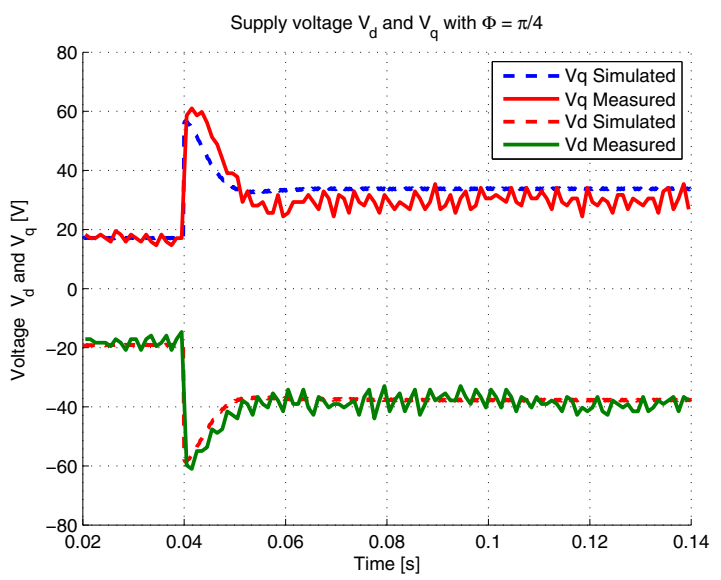

Fig. 16. Supply voltage $V_{d}$ and $V_{q}$ in a rotating frame $\Phi=\pi / 4$

on frequency as a specific applications require. These results are confirmed with experimental validation and numerical simulations showing a good performance of the identification method.

\section{ACKNOWLEDGMENT}

This work has been carried out within the framework of the project StimTac of IRCICA (institut dde recherche sur les composants logiciels et matériel pour la communication avancé), and the Project Mint of Inria.

\section{REFERENCES}

[1] Saleem, M. Salah, N. Ahmad, and V. Silberschmidt, "Control of ultrasonic transducers for machining applications," in 2013 9th International Symposium on Mechatronics and its Applications (ISMA), 2013.

[2] C. Giraud-Audine, T. H. Nguyen, M. Amberg, B. Lemaire-Semail, G. Abba, and R. Bigot, "Control of a multi-degree of freedom worktool for vibrations assisted forging," in 2014 IEEE/ASME International Conference on Advanced Intelligent Mechatronics (AIM), 2014.

[3] M. Takasaki, Y. Maruyama, and T. Mizuno, "Resonance Frequency Tracking System for Langevin Type Ultrasonic Transducers," in Mechatronic Systems Simulation Modeling and Control, A. M. D. Di Paola and G. Cicirelli, Eds. InTech, 2010.

[4] F. Giraud, B. Semail, and J.-T. Audren, "Analysis and phase control of a piezoelectric traveling-wave ultrasonic motor for haptic stick application," IEEE Transactions on Industry Applications, vol. 40, no. 6, pp. 15411549, Nov. 2004.

[5] F. Pigache, F. Giraud and B. Lemaire-Semail: Modelling and identification of a planar standing wave ultrasonic motor. Identification of a planar actuator, Eur. Phys. J. Appl. Phys. 34, 55-65 (2006).

[6] W. Ben Messaoud, F. Giraud, M. Amberg, M.-A. Bueno, B. LemaireSemail, "Closed-Loop Control for Squeeze Film Effect in Tactile Stimulator," International Conference and exhibition on new actuators and drives (Actuator 2014).

[7] F. Giraud, M. Amberg, and B. Lemaire-Semail, "Design and control of a haptic knob," Sensors and Actuators A: Physical, vol. 196, pp. 7885, Jul. 2013

[8] B.-G. Loh and P. I. Ro, "An object transport system using flexural ultrasonic progressive waves generated by two-mode excitation," IEEE Transactions on Ultrasonics, Ferroelectrics, and Frequency Control, vol. 47, no. 4, pp. 994-999, Jul. 2000.

[9] F. Giraud, C. Giraud-Audine, M. Amberg, and B. Lemaire-Semail, "Vector control method applied to a traveling wave in a finite beam," IEEE Transactions on Ultrasonics, Ferroelectrics, and Frequency Control, vol. 61, no. 1, pp. 147158, Jan. 2014

[10] T. Ohtani, N. Takada, and K. Tanaka, "Vector control of induction motor without shaft encoder," IEEE Transactions on Industry Applications, vol. 28, no. 1, pp. 157164, Jan. 1992.

[11] T. Sashida and T. Kenjo, An Introduction to Ultrasonic Motors. Clarendon Press, 1993.

[12] L. Shuyu, "Sandwiched piezoelectric ultrasonic transducers of longitudinal-torsional compound vibrational modes," IEEE Transactions on Ultrasonics, Ferroelectrics, and Frequency Control, vol. 44, no. 6, pp. 1189-1197, Nov. 1997.

[13] E. Moreno, P. Acevedo, M. Fuentes, A. Sotomayor, L. Borroto, M. E. Villafuerte, and L. Leija, "Design and construction of a bolt-clamped Langevin transducer," in 2005 2nd International Conference on Electrical and Electronics Engineering, 2005, pp. 393-395

[14] P. Vasiljev, D. Mazeika, and S. Borodinas, "Minimizing heat generation in a piezoelectric Langevin transducer," in Ultrasonics Symposium (IUS), 2012 IEEE International, 2012, pp. 2714-2717.

[15] A. Iula, "Design and Experimental Characterization of a Multifrequency Flexural Ultrasonic Actuator," IEEE Transactions on Ultrasonics, Ferroelectrics and Frequency Control, vol. 56, no. 8, pp. 1725-1730, 2009.

[16] K. Hynynen, N. McDannold, N. Vykhodtseva, and F. A. Jolesz, "Noninvasive MR Imaging-guided Focal Opening of the Blood-Brain Barrier in Rabbits," Radiology, vol. 220, no. 3, pp. 640-646, Sep. 2001.

[17] B. Fu, T. Li, and T. Hemsel, "Multiobjective Optimal Design of Symmetrical Langevin Transducers," in International Joint Conference on Computational Sciences and Optimization, 2009. CSO 2009, 2009, vol. 2, pp. 1017-1020.

[18] J. L. Rose, Ultrasonic Waves in Solid Media.Cambridge University Press, 2004.

[19] J. Yong and J.-F. Rouchon,"Resonant piezoelectric force sensor using two bending differential modes," in 2011 IEEE International Symposium on Industrial Electronics (ISIE), 2011, pp. 1307-1312. 